\title{
El uso de antiagregantes plaquetarios es efectivo para prevenir la preeclampsia
}

\author{
Antiplatelet agents are effective for the prevention of preeclampsia
}

Askie L et al. Lancet. 2007; 369: 1791-98

\section{Objetivo}

Evaluar la eficacia de los antiagregantes plaquetarios en la prevención primaria de la preeclampsia, y explorar qué subgrupo de mujeres se beneficiaría más, realizando un metanálisis de pacientes individuales*.

\section{Fuente y selección de datos}

Registro de ensayos clínicos Cochrane, que incluye búsquedas en Medline, Cochrane Library, revistas importantes y estudios no publicados. Se incluyeron ensayos clínicos aleatorizados realizados en 33 países entre 1985 y 2005, de mujeres en riesgo de desarrollar preeclampsia, y a las que se les había administrado uno o más antiagregantes plaquetarios vs. placebo.

\section{Resultados principales}

Se presentan los resultados de 31 estudios, con 32217 mujeres reclutadas en un ámbito de prevención primaria, y sus 32819 bebés. El análisis principal comparó el efecto de los antiagregantes plaquetarios vs. placebo para cada resultado final: preeclampsia, muerte intraútero o neonatal previa al alta hospitalaria, nacimiento pretérmino, bajo peso para la edad gestacional (BPEG) y embarazo con serios resultados adversos (incluyendo a cualquiera de los cuatro anteriores o muerte materna).

El $8 \%$ de las mujeres desarrolló preeclampsia $(n=2599)$. Comparados con el grupo control, los antiagregantes plaquetarios se asociaron con una reducción significativa en el riesgo de desarrollar preeclampsia, parto pretérmino y embarazo con resultados adversos graves; sin diferencias significativas para BPEG y muerte intraútero o neonatal ni para los efectos adversos potenciales como hemorragias pre y post-parto y desprendimiento prematuro de placenta normoinserta. Aunque el efecto relativo fue similar en los diferentes subgrupos, como el beneficio absoluto de los antiagregantes depende del riesgo basal de la mujer, el efecto absoluto y el número necesario a tratar cambiarán según el perfil de riesgo, como lo muestra la tabla 1.
Tabla 1: impacto preventivo de los antiagregantes sobre el riesgo de varias condiciones clínicas de acuerdo al riesgo basal de padecerlas.

\begin{tabular}{|c|c|c|c|}
\hline \multicolumn{2}{|c|}{$\begin{array}{l}\text { Riesgo basal o incidencia del evento a } \\
\text { prevenir en la población no anti-agregada }\end{array}$} & \multirow{2}{*}{$\begin{array}{c}\text { RR (IC 95\%) } \\
0,90(0,84 \text { a } 0,97) \\
\end{array}$} & \multirow{2}{*}{\begin{tabular}{|c|} 
NNT (IR95\%) \\
$56(35$ a 185) \\
\end{tabular}} \\
\hline Preeclampsia & $18 \%$ & & \\
\hline & $\begin{array}{l}6 \% \\
2 \%\end{array}$ & & $\begin{array}{l}167(104 \text { a } 556) \\
500(313 \text { a } 1667)\end{array}$ \\
\hline $\begin{array}{l}\text { Parto pretérmino (antes de } \\
\text { las } 34 \text { semanas) }\end{array}$ & $\begin{array}{c}20 \% \\
10 \% \\
2 \% \\
\end{array}$ & $0,90(0,83$ a 0,98$)$ & $\begin{array}{c}50(29 \text { a } 250) \\
100(59 \text { a } 500) \\
500(294 \text { a } 2500)\end{array}$ \\
\hline Muerte perinatal & $\begin{array}{l}7 \% \\
4 \% \\
1 \% \\
\end{array}$ & $0,91(0,81$ a 1,03$)$ & $\begin{array}{c}159(75 \text { a } 476) \\
278(132 \text { a } 833) \\
1111 \text { (526 а } 3333)\end{array}$ \\
\hline $\begin{array}{c}\text { Bajo peso para la edad } \\
\text { gestacional }\end{array}$ & $\begin{array}{c}15 \% \\
10 \% \\
1 \% \\
\end{array}$ & $0,90(0,81$ a 1,01$)$ & $\begin{array}{cc}67 & (35 \text { a } 667) \\
100 & (53 \text { a } 1000) \\
1000 & (526 \text { a } 10000)\end{array}$ \\
\hline $\begin{array}{c}\text { Embarazo con evento adverso } \\
\text { grave }\end{array}$ & $\begin{array}{c}25 \% \\
15 \% \\
7 \% \\
\end{array}$ & $0,90(0,85$ a 0,96$)$ & $\begin{array}{c}40(27 \text { a } 100) \\
67(44 \text { a } 167) \\
143(95 \text { a } 357) \\
\end{array}$ \\
\hline
\end{tabular}

NNT: número de embarazadas que debe recibir antiagregación para evitar un evento no deseado.

\section{Conclusiones}

Loa antiagregantes plaquetarios se asocian a una moderada pero consistente reducción en el riesgo de desarrollo de preeclampsia, nacimiento pretérmino y embarazo con eventos adversos graves.

Palabras clave: embarazo, preeclampsia, aspirina

Key words: pregnancy, pre-eclampsy, aspirin.

Fuente de financiamiento: National Health and Medical Research Council.

\section{Comentario}

El 5 al $10 \%$ de las embarazadas de Argentina desarrolla preeclamsia ${ }^{1}$, siendo los trastornos hipertensivos responsables del $15 \%$ de las muertes maternas ${ }^{2}$ y asociándose con un aumento de 20 veces en la mortalidad perinatal. Se han realizado múltiples intentos por desarrollar estrategias preventivas (antioxidantes, calcio, oxido nitrico) y aún no hay evidencia suficiente para recomendar estas estrategias, de allí el valor del estudio que resumimos. De acuerdo a los resultados de este metaanálisis de pacientes individuales ${ }^{*}$, sería válido informar a nuestras pacientes sobre un leve pero aparentemente verdadero efecto protector de la aspirina sobre algunos resultados adversos del embarazo. Si bien este estudio no pudo documentar diferencias de efectos en los distintos subgrupos y a primera vista pareciera tentador ofrecer dicha intervención en forma indiscriminada, todavía no contamos con información sobre su costo-efectividad y menos en nuestro medio. En países como el nuestro, en donde existe una alta prevalencia de preeclampsia y una alta morbimortalidad materna y fetal por esta causa, el uso de antiagregantes plaquetarios debería considerarse seriamente.

\section{Conclusiones de las comentadoras}

Por ahora, sería razonable recomendar el uso de aspirina en dosis antiagregantes a las mujeres con factores de riesgo de preeclampsia como edad añosa u obesidad. De todas maneras, por su bajo costo y su aparente inocuidad, podría comenzar a considerarse la indicación de aspirina a población general.

Catalina Brosens [ Servicio de Medicina Familiar y Comunitaria, Hospital Italiano de Buenos Aires. catalina.brosens @ hospitalitaliano.org.ar ] Natalia Basualdo [ Hospital Ramón Sardá ]

Recibido el 22/10/07 y aceptado el 14/04/07.

Brosens C. El uso de antiagregantes plaquetarios es efectivo para prevenir la preeclampsia. Evid Act Pract Ambul. 11(2) 39. Mar-Abr 2008. Comentado de: Askie L. et al. Antiplatelet agents for prevention of preaeclampsia: a metaaanalysis of individual patient data.Lancet. 2007 May 26; 369: 1791a98. PMID 17512048.

1. Rivero M y col. Impacto de la presencia de preeclampsia-eclampsia sobre los resultados perinatales. Revista Médica del Nordeste - № 7 - Octubre 2005 12. Disponible en URL: http://med.unne.edu.ar/fisiologia/revista7/resultadosperinatales.pdf (último acceso 17/04/08). 2. Ramos S, Romero M, Karolinski A, Mercer R, Insua I, del Río Fortuna C editores. Para que cada muerte materna importe. Pag. 81-101. 2004 CEDES. ISBN: 950-9572-25-X. 